\title{
Overview of Intervention Programs for Parents of Young Children (0 - 6)
}

\author{
Merav Goldblatt, Rivka Yahav, Tsameret Ricon \\ Faculty of Social Welfare \& Health Sciences, University of Haifa, Haifa, Israel \\ Email: tricon@univ.haifa.ac.il
}

Received 8 June 2014; revised 5 July 2014; accepted 1 August 2014

Copyright (C) 2014 by authors and Scientific Research Publishing Inc.

This work is licensed under the Creative Commons Attribution International License (CC BY). http://creativecommons.org/licenses/by/4.0/

(c) (i) Open Access

\section{Abstract}

In most of the world's societies and cultures, the biological mother and father bear primary responsibility to care for their child's needs and to guide him or her through the process of entry into society [1]. The parent serves, for the most part, as the significant figure with the greatest amount of influence over the child's life. Through his parent, the child learns the skills necessary to experience the world and function in it, whether the skills are in relation to survival needs such as eating, washing and mobility or developmental and social needs such as forming social relationships and developing the capacity to think and learn through play and supervision [2]. Thus the parent plays a critical but complex role in the development of his or her child, a role that requires development of a wide range of new behavioral, communicational, cognitive and emotional skills and capabilities in order to understand and cope with the challenges of child-rearing. Similarly, parenting styles and characteristics are influenced by a number of variables: The parent, the child, the interaction between them, and environmental variables such as culture, socio-economic status, and the existing family unit [2]. When children who suffer from behavioral difficulties do not receive the parental care they need, there is reasonable cause for concern that difficulties will develop in adulthood in a range of life areas that will have an impact on their lives and well-being and on their ability to adapt to society and contribute to it [3]. Accordingly, over the past 50 years parent-training programs have been developed to strengthen parents through learning and providing tools of experience and developmental knowledge, for the purpose of promoting the child's sense of wellbeing and quality of life [2] [4]. Objective: The purpose of this review is to provide an overview of evidence-based interventions for parents of young children ( 0 - 6), programs that are currently active in Israel and in the world, and to explicate the significant characteristics common to them that contribute to their effectiveness and success.

\section{Keywords}

Interventions for Parents, Early Development, Young Children, Review 


\section{Introduction}

Raising a child in a nurturing and enriching environment while providing warmth, love and encouragement, in secure boundaries, is one of the parent's main functions [5]. When children who suffer from various difficulties do not receive the parental care they need, there is a reasonable cause for concern that difficulties will develop in adulthood in a range of life areas that will have an impact on their lives and well-being and on their ability to adapt to society and contribute to it [6]. Accordingly, over the past 50 years parent training programs have been developed to strengthen parents through learning and providing tools of experience and developmental knowledge, for the purpose of promoting the child's sense of wellbeing and quality of life [2] [4].

The purpose of this document is to provide an overview of evidence-based interventions currently active in Israel and in the world for parents of young children $(0-6)$, and to explicate the significant common characteristics that contribute to their effectiveness and success.

\subsection{Parent's Role and Early Detection}

In most of the world's societies and cultures, the biological mother and father bear primary responsibility to care for their child's needs and to guide him or her through the process of his entry into society [1]. The parent serves, for the most part, as the most significant and influential figure in the life of the child. The parent is also a medium for the child to learn problem-solving skills, as their lives together with the inevitable problems along the way provide endless opportunities for learning [2] [5].

The motor, cognitive, emotional and social development of children aged 0 - 6 influences and shapes their later lives [5]. Parenting itself is a necessary component in child development in all area of life. Through his parent the child learns the skills necessary to experience the world and function in it, whether the skills are in relation to survival needs such as eating, washing and mobility or developmental and social needs such as forming social relationships and developing the capacity to think and learn through play and supervision [2]. Good parenting has been found to be a predictor of positive social, behavioral, emotional and academic adjustment. In contrast, problematic parenting has been found to be a predictor of antisocial behavior and functional difficulties later on in life [7]. Thus the parent plays a critical but complex role in the development of his or her child, a role that requires development of a wide range of new behavioral, communicational, cognitive and emotional skills and capabilities in order to understand and cope with the challenges of child-rearing. Similarly, parenting styles and characteristics are influenced by a number of variables: The parent, the child, the interaction between them, and environmental variables such as culture, socio-economic status, and the existing family unit [2].

Parenting requires one to develop new skills in order to understand and cope with raising the child. For example, behavioral problems that disturb daily routines and include aggression, resistance and disobedience are regularly seen among children [8]. When children who suffer from these behavioral difficulties do not receive the required care there is reasonable cause for concern that difficulties will arise in adulthood in a range of life areas: learning, work, interpersonal relations, addictions (alcohol, drugs), as well as development of emotional difficulties and psychiatric diagnoses [9] [10]. In addition, one of the significant findings in longitudinal studies that examine antisocial and criminal behavior is that chronically antisocial behaviors that appear early in life usually lead to criminal behavior and lives of crime later on. In light of this, it is extremely important that policies for intervention and prevention should start in early childhood [3]. Early investment, in early childhood, empowers the child in the family context, increases the chances of successful integration in educational, social, and community frameworks, and prevents the need for intervention at later stages [2].

\subsection{Parent Training Programs}

Identification of the significant effect of parental behavior during early stages of life upon child development and behavior precipitated the need to develop modes of therapeutic work with parents [4] [5]). Therapeutic work with parents exists in a number of forms and models, including a number of types of intervention in which the parent is not the main focus, with therapy defined as "with" the parent (Parental therapy/guidance), and interventions in which therapeutic work focuses on the parent himself (Parenthood Therapy) [11]. Three types of common interventions with parents can be identified:

1) Meeting with parents in parallel to child therapy-The emphasis is on child therapy and the parent is accompanied and connected to the process the child is undergoing. The change in the parent will take place indirectly and especially as a result of his own independent work. 
2) Parental guidance-The emphasis is upon changing patterns of parenting, with or without child therapy. This is a psycho-educational intervention that includes teaching models of child development as a basis for understanding the child's needs, and advice on effective parenting derived from both cognitive and dynamic schools of thought.

3) Therapeutic interventions with parents in the context of dyadic (relational) therapy or parent-child therapy-This intervention can sometimes have significant and deep, though indirect impact on parenting.

In this document we will focus on intervention programs with the parent (mostly 2 and 3 above). Beginning in the 1960's a number of research groups began to develop parent training programs which by now have a broad base of research [2]. This relates to programs that strengthen parenting through learning and provision of tools of experience and developmental knowledge [11], with the ultimate goal of promoting the child and parent's sense of wellbeing and quality of life [2] [4] [12].

The parent training programs developed over the years are many and diverse. The programs differ with regard to the models and methodologies that underlie them, so that while the emphasis in some of the programs is solely on didactic learning (technical transfer of structured knowledge via a lecture or watching a movie), others place an emphasis on learning through doing, where the parent learns skills by practicing with the child and the therapist in the clinic and in a natural setting [4] [13] [14]. Similarly, programs are characterized by a diverse range of content (developmental knowledge about the child, parental sense of agency, communication skills, strategies of behavioral management and more); turn to different target populations (special and regular populations); and include different settings (clinic, home visits, parent groups, and individual therapy). The programs also expanded to include not only behavioral problems but also to relate to and improve the child's cognitive development, anxieties, and general health [12].

\subsection{Training Programs Characteristics}

Despite the existing difference and diversity, training programs for parents include similar characteristics, with the most important being: 1) evaluating the problems and difficulties that the parents are facing; 2) training the parent to use new coping skills; 3) practicing use of these skills with the child; 4) feedback on implementation of the skills [15]. In most of the programs the primary work of the therapist with the parent(s) is identifying and interpreting the child's behavior and developing the skills required for coping accordingly.

The parents experience different techniques of role play, group or individual discussion, watching training movies and getting feedback in order to actively practice the use of strategies vis a vis the child. Many programs include homework in order to improve the likelihood of generalization and transfer of the knowledge and experience gained in the clinic under controlled conditions, to the dynamic environment in the home [2] [8].

\subsection{Parent Training in the Light of Research}

On the whole it seems that programs led by therapists have proven to be effective in promoting positive change in the behavior of both child and parent, in the communication between them, and in improving the self-image of the parent [2] [8] [12] [16]. Studies that examined the effectiveness of programs over time showed that the influence of these programs is maintained over time and can contribute to lessening the child's behavioral difficulties and antisocial and criminal behavior in his later life and in all areas of life [3].

\section{Intervention Programs}

Intervention programs can be divided into three main sections: 1) Interventions type; 2) Intervention categorized by professions (nursing, occupational therapy, nutrition, communication disorders and psychology); 3) Intervention directed to specific type of populations. Interventions for parents are surveyed with regard to the background, rationale and goals, in addition to a description of the process and effectiveness. In reviewing the current research we will address whole sections. We will also review two additional categories: Parent-child intervention programs prevalent in the world and popular intervention programs that are not evidence-based. A summary of the categorized intervention programs is added in Table 1.

\subsection{Interventions Categorized by Professions}

Parent-Child Interventions in Sleep Difficulties

Today it is well known that sleep fills important functions in the first years of development, including the de- 
Table 1. List of the categorized intervention programs.

\begin{tabular}{|c|c|c|c|}
\hline $\begin{array}{l}\text { Interventions categorized by } \\
\text { professions }\end{array}$ & $\begin{array}{l}\text { Overview of parent-child } \\
\text { intervention programs by } \\
\text { population }\end{array}$ & $\begin{array}{l}\text { Parent-child intervention } \\
\text { programs prevalent in the } \\
\text { world }\end{array}$ & $\begin{array}{l}\text { Popular intervention programs } \\
\text { that are not evidence-based }\end{array}$ \\
\hline $\begin{array}{l}\text { 1) Parent-child interventions in sleep } \\
\text { difficulties }\end{array}$ & $\begin{array}{l}\text { 1) Four parent-child } \\
\text { intervention programs } \\
\text { during pregnancy }\end{array}$ & 1) Living with children & $\begin{array}{l}\text { 1) PET-Parent } \\
\text { Effectiveness Training }\end{array}$ \\
\hline $\begin{array}{l}\text { 2) Occupational therapy: Three } \\
\text { Intervention Programs }\end{array}$ & $\begin{array}{l}\text { 2) Overview of mixed } \\
\text { programs for } \\
\text { single-parent mothers }\end{array}$ & 2) The incredible years & $\begin{array}{l}\text { 2) STEP_Systematic } \\
\text { Training for Effective } \\
\text { Parenting }\end{array}$ \\
\hline $\begin{array}{l}\text { 3) Physical therapy: Five } \\
\text { intervention programs }\end{array}$ & $\begin{array}{l}\text { 3) Intervention programs } \\
\text { for fathers }\end{array}$ & $\begin{array}{l}\text { 3) HNC_-Helping The } \\
\text { Noncompliant Child }\end{array}$ & $\begin{array}{l}\text { 3) Triple P: Positive } \\
\text { Parenting Program (USA) }\end{array}$ \\
\hline $\begin{array}{l}\text { 4) Communication disorders: Two } \\
\text { intervention programs in the areas of } \\
\text { language and literacy. }\end{array}$ & $\begin{array}{l}\text { 4) Healthy family } \\
\text { America for at-risk } \\
\text { populations }\end{array}$ & $\begin{array}{l}\text { 4) PCIT_Parent Child } \\
\text { Interaction Therapy }\end{array}$ & $\begin{array}{l}\text { 4) EHS—Early Head Start } \\
\text { (USA) }\end{array}$ \\
\hline \multicolumn{4}{|l|}{$\begin{array}{l}\text { 5) Nutrition: Community interven- } \\
\text { tion to promote healthy life habits } \\
\text { among children and youth }\end{array}$} \\
\hline $\begin{array}{l}\text { 6) Psychology: Three parent-child } \\
\text { intervention programs focused on } \\
\text { attachment }\end{array}$ & & & \\
\hline
\end{tabular}

velopment of the nervous systems, growth, motor development, behavioral and emotional regulation, and cognitive functioning [17]-[21]. Sleep disturbances at a young age are among the most common complaints presented by parents to pediatricians and other professionals, at a rate of $20 \%$ - 30\% [22]. These complaints include difficulties falling asleep and waking up during the night, called in professional language "childhood behavioral insomnia” [23].

Sleep difficulties are a product of the interaction between parents and children and therefore any therapeutic intervention needs to be directed at changing the behaviors of parents and children. Since many parents have mistaken perceptions and lack knowledge about proper sleep patterns and habits among children, and this expresses itself in over-involvement and in difficulties in setting clear limits regarding sleep, interventions rely upon a cognitive-behavioral approach. The behavioral component is designed to extinguish the positive conditioning that was created when at the time parents, when putting their child to sleep, are busy trying to calm the child (for example: rocking the carriage, driving in a car, or falling asleep in the parent's bed) instead of allowing him to develop mechanisms for self-calming and the ability to fall asleep on his own.

Treatment of sleep disturbances at a young age is important not only from a developmental perspective [21]. Sleep disturbances tend to be maintained for years [24], and they have a significant impact on the emotional wellbeing and quality of life of the parents [25].

There is a great deal of evidence in the scientific literature about the effectiveness of parenting interventions for treating or preventing sleep disturbances among young children (0 - 6) [26]-[28]. These interventions include psycho-educational counseling to parents, behavioral extinction (full or gradual), and building a sleep routine. Cognitive Behavioral Therapy for Insomnia (CBT-I) is today considered the treatment of choice for insomnia among adults [29], and its long-term effectiveness is even greater than medication therapies [30]. This treatment has been found effective also for behavioral insomnia among children, with a success rate of $94 \%$ in reducing problems of falling asleep and wakening during the night, and 82\% in follow-ups over periods of 3 - 6 months [31]. The physiological factors in early childhood sleep disorders are clear, including breathing disorders in sleep, asthma and disturbances in the digestive system. Treatments can be provided before or in parallel to cognitive-behavioral treatment.

The system of beliefs, expectations and interpretations of parents about their children's sleep are related to as a basis for leading to a change in behavior. These cognitions are often related to issues of setting limits, limiting parental involvement and the interpretation given to the meaning of the child's waking up at night. Parents enhance their knowledge and awareness about sleep and learn strategies for promoting healthy sleep habits in early childhood. The emotional component of the parents is also related to, including expression of fears about the child's resilience and his ability to manage with limited parental involvement during the night, as well as feelings of guilt, doubts and resistances to treatment. Cognitive treatment before beginning behavioral interventions 
often increases parental compliance.

Extinction of the positive conditioning that developed when parents were involved in calming the child during the night, by gradually decreasing parental involvement. According to this method, in the course of putting the child to bed, the parent gives the child a clear message that he is not alone, but that he must fall asleep on his own. The parent leaves the child in the bed and comes for a brief visit at fixed intervals (typically every 5 minutes), until the child falls asleep. This process lasts for a number of days until the child learns to fall asleep on his own without crying or protest. During visits the child should not be taken out of the bed, and the visit should be kept brief (one minute or less). In addition, parents should be helped to establish a fixed sleep routine every night and to be consistent with it over time. It should be taken into account that the child will express protest during the course of this process, and many parents will have difficulty coping with this resistance and maintaining the changes, fearing that they may be causing their child harm.

This treatment is found to be effective in many studies and to this day no negative effects have been reported regarding the behavioral method [21].

\subsection{Occupational Therapy: Three Intervention Programs}

Background: In recent decades pediatric occupational therapists have developed early intervention programs designed to improve parents' sense of competence, based on relationships of partnership with families and with an emphasis on the interaction between the parent and child [32]-[33].

Rationale and goals: In most of the early intervention programs the occupational therapists place an emphasis upon parent participation in play activities in order to teach them about the needs of the child and about their own needs as parents [34]. It is important to note that some of these intervention programs are in the consultation model of the occupational therapist and some include a model of direct intervention, even though no significant difference has been found in the effectiveness of either model [35]. The professional literature shows that the therapist's focus on strengthening the parent-child interaction and improving their attachment patterns leads to an improvement in additional developmental components, such as the child's cognitive development over the years [36]. Similarly an emphasis is placed in the interventions on the relationship between improved parental sensitivity to "signs" that the child transmits and an improvement in the level of "playfulness" and motivation of the child, the degree of the child's independence and inquiry, and his capacity for social interaction [37].

\section{Modes of intervention:}

1) A prevention program held for mothers of typical babies in lower socioeconomic neighborhoods in Jerusalem [33].

In this program mothers held meetings once every other month with an occupational therapist in the Tipot Halav, during the course of the child's first year. These meetings included providing information and modeling for the mother about sensory-motor, language and cognitive activities.

Effectiveness of the intervention: In a study of the effects of the program after about two years it was found that the mothers in the intervention group had more knowledge about child development, improved perceptions of their ability to contribute their child's wellbeing and development, and better implementation of developmental knowledge compared to a control group.

2) An early intervention program for mothers of typical young children (ages 2.5 - 3 years) [34] that was implemented in Australia.

The goal of this intervention program was to encourage mother-child interaction by means of play and to expand the mother's knowledge about child development. The intervention took place over the course of ten weekly meetings and was based on the activity of preparing a game or demonstrating games. In the program the following outcome measurements were taken before the intervention, at its conclusion, and after one and a half years: The way the mother relates to causality with regard to the child's behavior, the extent of parental tension, the mother's self-image as an educator, the child's temperament and behavior.

Effectiveness of the intervention: While no change was found in the quantitative outcome measures between the intervention group and the control group, participants were found to be satisfied with the intervention program, and they reported that they implemented the knowledge they had gained in initiating playgroups of mothers in the community.

3) A group intervention of occupational therapists on the issue of time management and improving mothers' occupational performance. 
Mothers were given support and provided with various strategies for improving family time management (establishing family rules, delegating responsibility, managing time demands and more) [38].

Effectiveness of the intervention: Focus groups were held in which mothers reported on feelings of personal empowerment, wellbeing with regard to child care and the learning of strategies for coping with daily tasks and the burdensome routine [39].

Additional important principles for successful intervention:

- Focus on the parent-child interaction as a "therapeutic tool, evaluating the parents' perceptions and values, providing the parent with positive reinforcement and including him in the therapeutic process" [40]. Moreover, in terms of the strategies occupational therapists use during early interventions, it was found that the most effective strategies are creating joint interaction of the therapist with the parent and child, and taking advantage of the learning opportunities that present themselves during the course of the interaction [41].

- Occupational therapist's relating to the management of the mothers' time while designing early interventions [42] [43]. This in order that the interventions will fit in with family routines, will not place a burden on the already overburdened mothers of young children, and will contribute to the mother's quality of life and to the wellbeing of the family [44].

- Understanding the home environment and the objects in it in order to integrate intervention goals with the family routine and daily play situations [45]. In a study that examined the way in which mothers managed the home environment in order to encourage developmental play of typical babies aged 1 - 18 months [46] it was found that mothers had different strategies for managing play objects in the house and for organizing and maintaining the home environment so that it would support the infant's development.

\subsection{Physical Therapy: Five Intervention Programs}

Background: Around the 1980's professionals began to get a deep appreciation of the importance of early intervention programs, especially during early childhood. Most of the intervention programs in the field of physical therapy are hands-on programs, in other words the treatment is mostly performed by skilled physical therapists.

Rationale and goals: In the last decade there is an increased appreciation of the role and importance of the parent in treatment, and it subsequently has received a central place in research studies. Involving parents in treatment itself, whether as assistants to the therapist or as providers of treatment themselves, improves the parent's understanding and ability to help his child on both the motor and mental levels, promotes the child's development and achievement of developmental milestones, and helps the parents to create a safe environment adapted to their child [47].

Modes of intervention:

Studies chosen for the survey are examples of studies in which physical therapy counseling to parents, whether of children at risk or children with developmental disorders, is a core program component:

1) The effectiveness of mother-child counseling relative to learning the technique of NDT therapy, for mothers whose babies have been diagnosed with CP at the age of 8 - 32 months [48] (USA).

In the context of the intervention mothers in the experimental group were supervised by a physical therapist, and taught how to improve the mother-baby interaction with an emphasis on adjusted positioning, while mothers in the control group received NDT therapy and were supervised in only one technique in accordance with the baby's needs.

Effectiveness of the intervention: Outcomes showed significant success in changing the behavior of the mother and baby in the experimental group-mothers were more engaged in positive initiative/coaching and in face-to-face response, than mothers in the control group. In addition, babies in the experimental group responded better to their mothers. This change in the behaviors of mothers and babies is considered significant to the child's independent development in the rest of his life.

2) An intervention program for improving the motor abilities of premature infants [49] (Thailand).

A sample was taken from the intervention population of premature infants (born prior to week 37) with no genetic abnormal disorders, without bleeding in the brain, operations, hydrocephalus or Retinopathies. The intervention program included a total of 12 activities per child by the main therapist, from standard week 40 . Every week until the age of 3 months, training and practice took place in the subjects' homes. Babies were checked by the TIMP test for neuro-motor behavioral assessment and the therapist was interviewed. In addition 
the therapists were asked to demonstrate the exercises and everything was documented on video.

Effectiveness of the intervention: While there was a significant improvement in the TIPM results in the experimental group in a measurement at 4 months of age, no difference was found between groups.

3) Counseling of new mothers with the goal of lessening the risk for postpartum depression, which is a risk factor for the baby's motor and emotional development [50] (Australia).

The intervention program lasted eight weeks and included an hour of joint physical activity for mothers and babies and a half hour lesson on healthy living. The intervention began in the $6^{\text {th }}-10^{\text {th }}$ week after birth.

Effectiveness of the intervention: Researchers found a significant improvement in the rating of well-being and a decreased level of depression in the experimental group in comparison to the control group. This study shows that routine use of a program of exercise and healthy lifestyle education can reduce long-term problems such as postpartum depression.

4) An early intervention program called COPCA (Coping with and Caring for Infants with special needs) is focused on the family of a baby with CP in comparison with physical therapy using the NDT method [51] (Holland).

The study was performed with two groups, one of traditional physical therapy in accordance with the NDT, and the second with COPCA. Treatment was provided by licensed physical therapists once a week over the period of a year in the family's home.

Effectiveness of the intervention: Outcomes were not provided, but the researchers assume that COPCA will have positive outcomes because the program provides parents with positive strategies for coping with different situations, and consequently it should lead to better results on the child's motor and cognitive tests.

5) A para-professional home-visiting program for an at-risk, low socioeconomic population [52] (USA).

The program accompanies first-time parents, beginning during pregnancy, in the home. The goals of the program are to promote pregnancy health, child development, and mother's wellbeing. Home visits continued until the age of two, becoming more frequent as pregnancy advanced, and after birth visits were once a week and then every other week.

Effectiveness of the intervention: The study found lower percentages of child abuse, fewer immediate pregnancies, a higher quality of mother-child interaction, less behavioral problems among the children, and better language development among the research population.

\subsection{Communication Disorders: Two Intervention Programs in the Areas of Language and Literacy}

Background: Many studies show that language development, like the early signs of literacy, takes place long before the child meets the formal educational settings such as the daycare center, pre-school setting and school. Already in the first year of life, even before the appearance of the first words, there is a rich and complex communication between the baby and parent. Watching, making noises and use of gestures are the means at the baby's disposal, and their integration makes possible the development of reciprocal relations and communication with the environment [53]. In different studies it has been found that daily reading of stories and a reading style in which parents talk about the story and respond to the child's comments and questions, support the child's development of language, contribute to expanding his vocabulary and assist in improving his ability to understand and to express himself [53] [54]. It has also been found that reading stories encourages the child's awareness of the role and use of written language (Concept about Print) and awakens a positive attitude toward story reading [55]. Socio-interactive theories that seek to explain the process of language acquisition emphasize the importance of social support and contextual framing in the process of language development thereby highlighting the importance of reading stories in general and more specifically as part of an intervention program for children with language difficulties.

Rationale and goals: The concept underlying intervention programs in the area of language and literacy is that language is an important tool in the development of socialization in general and more specifically in the development of linguistic socialization. Active participation in verbal interactions promotes linguistic-social communication and shapes thinking and cultural values [56] [57]. In Israel there are many intervention programs sponsored by the Ministry of Education or various philanthropic organizations. These programs operate within the formal educational system only from the age of 3. Children from birth to age 3 who participate in formal frameworks under the auspices of organizations such as WIZO and NAAMAT, and under the supervision of the 
Ministry of Industry and Commerce, are mostly exposed to philanthropic intervention programs (for example of the Caring Commission of UJA-Federation of New York). From among the variety of programs offered throughout the world (and whose documentation can be found in the literature) that deal with support of families in need, the focus will be on those that meet the following criteria: Programs built on the basis of collection of longitudinal data on a wide range of measures in the home and in educational frameworks, data taken from a representative sample that makes possible conclusions and generalizations, programs that examined their effectiveness with methods of Evidence Based Practice, those that clearly formulate the theoretical rationale underlying program design, and provide a detailed and comprehensive description of how it is carried out. The two programs that will be presented below begin with the assumption, proven in many studies, that development of linguistic capacity, the quality of verbal interaction between the child and his parents, and the nurturing of emergent literacy in pre-school years, are all strong predictors of school success [58] [59].

\section{Modes of intervention:}

1) The parent-child home program (USA) [60]. (http://www.cebc4cw.org/program/the-parent-child-home-program/detailed).

The target population is poor families, single-parent families, young parents, or immigrants. The program serves children aged 2 - 4 years, and places an emphasis upon the quality of linguistic interaction and communication between parents and children, on social and emotional development, and on nurturing emergent literacy as preparation for school. Work with families takes place in the home environment and the parents are exposed to a model of enriching interaction with the child. The goal of the intervention is to enhance the quality and quantity of verbal interactions, strengthening the parent's sense of self as a parent, developing language and literacy skills and increasing the child's social behavior. The program last for two years and the facilitators visit the family's home twice a week. Families receive books and toys that enrich the literacy environment in the home. The program does not offer the family activities beyond the time in which the facilitator is in the family's home. Facilitators undergo a sixteen-hour preparatory workshop and meet weekly in learning and support group (a detailed guide can be purchased with full details and recommendations for program implementation).

2) Home instruction for parents of preschool youngsters [61]. (http://www.cebc4cw.org/program/home-instruction-for-parents-of-preschool-youngsters/detailed).

This program is intended for children from birth to 5 years of age in families living in poverty whose home environments put them at high risk for developmental delay. The goal of the program is to foster language ability and emergent literacy in preparation for school. Program facilitators go into the family home but do not make direct contact with the children, rather they do role playing with the parents with regard to proposed activities and to how to establish communication with the child. Together with entry into the home the program also offers group meetings for parents in order to create a supportive and enriching parent group. The program last for three years but the frequency of meetings is not documented. In this program the families receive books and work books for activities with the children beyond the meetings with the facilitator (a guide can be purchased with all of the details and recommendations for program implementation).

\subsection{Nutrition: Community intervention to Promote Healthy Life Habits among Children and Youth}

Background: The project is intended to establish a community health promotion program in lower socioeconomic neighborhoods in Haifa. The need for such a program is clear in light of the evidence that lifestyle in early life has implications for development of chronic illnesses, such as heart disease and diabetes, at a later age, as well as implications for social functioning and quality of life during childhood and adulthood. Improving the quality of nutrition and level of activity among children is particularly important in light of the increase in rates of obesity, primarily in the lower socio-economic strata. It is important to emphasize that weight loss among children is not one of the program's goals. Instead the aim is to help parents and their children to adopt healthier lifestyles.

In early childhood the family environment is particularly important to the development of food preferences, eating habits and style, and exercise routines. Children's food consumption is influenced by their preferences and by their sense of hunger and satiation, but also by the type of foods that their parents put before them and make accessible. It has been demonstrated that when children are offered a variety of healthy foods they choose a diet that meets the criteria for a healthy diet with no need of parental intervention. Of course this situation is 
the opposite to what actually happens in an environment in which there is an abundance of processed foods loaded with calories and an encouragement of a sedentary lifestyle [62].

Intervention processes: Behavioral therapy is considered the first line of treatment for child and adolescent obesity. Behavioral therapy includes teaching parents and children about goal setting, preventing relapse, problem solving and managing the surrounding environment such that it will encourage good nutrition and physical activity. All of the programs that involve young children the parents are also involved, since it is they that mostly control their child's nutrition. Findings from different programs show that an effective program needs to focus on instructions for parents designed to foster eating patterns and food choices that are suitable to a healthy diet. Instruction to parents needs to include an explanation of how children develop eating habits in the family context. Practical instruction for parents includes tools for fostering choice of healthy foods and encouraging children to accept new food. Similarly, parents should be provided with information that is practical and easily understood about the size of portions appropriate for children, and suggestions about the timing and frequency of meals and stacks [63].

The program "Tailor-made for me" of the Israel Ministry of Education (www.tafuralay.co.il) is implemented both in pre-school settings and schools in Israel. The advantage of the program is that it is adapted to the Israeli population and its effectiveness has been demonstrated through research [62] [63]. The nutritional intervention was planned especially to improve knowledge about nutrition and includes learning topics through lectures and discussions. All of the sessions are led by pre-school teachers and are adapted to their level. In addition, the children bring their parents monthly information sheets that discuss various issues related to nutrition. The children are encouraged to share their nutritional information with their parents, and the parents are asked to discuss the issue with their children.

The primary goals are promoting healthy eating habits, an active lifestyle among the children and their parents, and developing a program for preventing child obesity. The program has additional more specific goals such as encouraging nursing and eating breakfast, limiting "television time", and more.

\subsection{Psychology: Three Parent-Child Intervention Programs Focused on Attachment}

Background: An important aspect of parenting is helping the child by providing appropriate responses and creating safe attachment, to develop his internal regulatory systems in a manner appropriate to the requirements of the environment [64]. The mother's state of attachment during pregnancy is found to be related to the quality and degree of the infant's level of security in attachment [65].

Difficulty in internal regulation occurs when the parent has difficulty providing appropriate care and can be expressed on the emotional, behavioral and physiological levels. Children whose needs were not met are at a high level of risk to develop difficulties in the long term that are related to problems in emotional and behavioral self-regulation such as a tendency to use addictive substances and criminal behavior. Thus parents need to provide the child with a same, predictable and controllable environment that supports the child in his development of self-regulatory skills [66]. Similarly, studies show that the mother's capacity to reflect on her functioning is a central component in her ability to transmit and create attachment to the child [65]. These findings support the building of interventions that give tools for reflective functioning, thereby encouraging creation of secure attachment between mother and child.

1) Attachment and bio-behavioral catch-up intervention (ABC) [67] (USA).

Rationale and intervention goals: In order to narrow biological, behavioral and emotional gaps related to the child's primary relational systems (attachment), an intervention program was designed that focused upon counseling the parent on how to develop his capacities to provide adapted responses and a secure environment. This program focused on a population of toddlers in foster families in order to examine the extent to which it is possible to rehabilitate disturbances in the child's primary attachments with his main caretakers. An additional assumption underlying the study was that early intervention would have more significant and extensive impact than interventions done in later years.

Course of intervention: The program focuses on development of the child's self-regulatory capacities. It includes three main intervention areas: Helping the (foster) parent to interpret the child's rejection behaviors, counseling the parent how to overcome their own issues that prevent them from providing nurturing care, and on how to provide the child with an environment that encourages development of self-regulatory capacities (helping the child to identify emotions and express them appropriately, providing appropriate sensory stimuli). The 
intervention program has an organized guidebook, with topics divided over ten weekly meetings, held in the family's home by a professional therapist, and activities are adapted to a range of ages. Meetings are active and include hands-on counseling together with the child, joint discussions. Sessions are filmed so that they can later be jointly analyzed.

Intervention Effectiveness: A random controlled experiment (RCT) performed with 60 children to evaluate the program found positive outcomes showing that performance of a formal time-limited program promoted the development of self-regulatory capacity among children in foster care. In the experimental group that participated in the program the children produced more appropriate levels of cortizol in comparison to the control group. In addition, parents of children in the experimental group reported fewer behavioral problems.

2) The Circle of Security Intervention (COS) [68] (USA).

Rationale and intervention goals: There is a great deal of evidence that the quality of attachment between the parent and child in the first years of life has an important impact on his development and on his becoming an independent adult. Insecure attachment is found in the literature to be a risk factor for development of psychopathology later in life.

Accordingly the goal of the program is to counsel the parent on how to be more attentive to the child and to himself in order to develop secure attachment. In addition, an emphasis is placed on self-evaluation of the parent-child attachment existing prior to performance of the intervention, so that the therapist can know what the child has learned about how to participate in a relationship with the parent and direct the intervention to his unique needs.

The course of intervention: The program is comprised of a set protocol including 20 weekly group meetings (5 - 6 parents) an hour and a quarter each. Meetings include therapeutic and educational components, and are led by a licensed psychotherapist. The protocols are based on attachment theory and are appropriate for both intervention and prevention. The program has five key components: a) Establishing the group as a safe space in which the parent can reflect upon his relationship with his child; b) Improving the parent's ability to provide his child with adapted and sensitive responses by learning about the child's basic attachment needs; c) Improving the parent's ability to interpret manifest and latent signs that the child exhibits to make its needs known; d) Increasing the parent's ability to feel empathy through use of reflections on the child's and parent's behaviors; e) Increasing the parent's ability to understand how his own developmental history affects his current abilities as a parent.

The first meetings are devoted to educational and didactic aspects of the issue of attachment. During the following meetings the therapist, following a set protocol, focuses on each parent and generates active discussions on each topic through the use of short video films.

Intervention effectiveness: A longitudinal study with measurements before and after the intervention examined whether parents and children from at-risk populations who participated in the program transitioned between types of parent-child attachment. Findings of the study were positive and showed that the program could help to reduce characteristics of insecure attachment for young children. About $70 \%$ of the children categorized as belonging to the "disorganized" type of insecure attachment were categorized following the intervention as belonging to the secure attachment group. The researchers attributed this change to the contribution of the program to the parent's ability to identify and reflect upon his own defensive strategies that previously had prevented him from responding sensitively and appropriately to the child's needs.

3) Video feedback intervention to promote positive parenting (VIPP) [69].

Rationale and intervention goals: The parent's mental representation of the characteristics of attachment and his behavior toward the child are influenced by his own internal representations of attachment and affect the quality of attachment with the child. The goal of the intervention is to strengthen and encourage the parent's sensitive and adapted response to the child's signs by filming the parent and child and giving feedback (the parent in a sense serves as his own model).

Course of intervention: This program is based on attachment theory and includes a set protocol in which the parent-child dyad is filmed in their home, and later watches the videos together with the therapist. During intervention meetings, held with a psychologist once a month for an hour and a half, the parent is given feedback and support when they show positive responses to the child.

Effectiveness of intervention: In a study performed on this intervention with mothers and babies around one year of age, the program was found to have positive effects on the level of adapted/sensitive responses provided by mothers to the child. At the same time, characteristics of secure attachment were not found to increase in the 
research sample following the intervention.

\section{Overview of Parent-Child Intervention Programs by Population}

\subsection{Four Parent-Child Intervention Programs during Pregnancy}

Background: Stress and negative mood during pregnancy are risk factors for the baby's development, for the mother's mood after birth, and for development of secure attachment between the parents and the baby. Relevant studies have found effects on low birth weight, early birth and difficulties during birth, low APGAR scores, difficulties in varying facial expressions in accordance with stimuli and more [70]-[72]. In addition the literature shows that the mother's psychopathology before and during pregnancy increases the risk that the child will develop emotional difficulties and difficulties in self-regulation [73]. Hence there is a need for an appropriate intervention with expecting parents during pregnancy and following birth in order to help them establish the foundations that will continue to serve the parents, the child, and the family unit.

\subsubsection{Psychodynamically Oriented Intervention [74] (USA)}

Rationale and goals: Psychodynamic interventions directed at treating the person's different conflicting representations have a significant advantage as preventive treatment for women with affective disorders during pregnancy, which may be triggered by distorted or unadjusted internal representations. The assumptions underlying the intervention are that it is important to reach an understanding of the mother's inner world in order to later have an impact of the process of the child's growth and development [74].

Course of intervention: Individual therapy done by a trained psychodynamic therapist. Therapy dwells on the woman, her personal history and her experience of pregnancy. This process expands the psychological space in which the imaginary baby can grow and become distinguished from problematic representations that were the product of the mother's early painful or unsatisfying experiences with her own mother [74].

Intervention effectiveness: No evidence is provided as to the effectiveness of the intervention.

\subsubsection{Mindful Motherhood Intervention [75]}

Rationale and goals: Literature shows that the experience of stress and strain during pregnancy has a direct impact upon birth and child development. The Mindfulness Method is a means for developing the capacity for observation that can bring about a change in mental or physiological state [76].

Intervention course: Intervention meetings are weekly over a period of eight weeks and are held in a group of 12 - 20 women for two hours at a time. Meetings are facilitated by a clinical psychologist with specialized training in the method, and they include three main methodologies for observing emotions and thoughts: 1) Learning and practicing breathing techniques; 2) Using guided meditation and yoga exercises; 3) Using and understanding psychological concepts such as acceptance.

Program meetings include lectures, discussions and practical exercises such as awareness of the developing fetus, discussion of anxieties about birth, calming walks, and more. In addition participants are given a disc with guided meditation and reading material to supplement what they learn in the meetings.

Intervention effectiveness: In a random controlled pre- and post-intervention pilot study done with 31 women it was found that use of this intervention program during pregnancy reduced negative mood, anxiety, and depressive feelings. In addition it was found that the intervention helped to improve and raise the mood of participants. The effects on the period following birth and on the baby's subsequent development were not studied.

\subsubsection{Family Foundations (FF) [76] (USA)}

Rationale and goals: During and following pregnancy many changes take place in the composition and management of the family unit. A central aspect of family life is the way in which the parents work together and support one another in coping with conflicts that arise around the raising of the child. The main goal of the program is to strengthen this cooperation and to accompany the changes that the parents undergo during pregnancy and after the birth, by encouraging support and coordination in the relationship [76].

Course of intervention: The program is delivered in local hospital departments as part of a program of birth education, is intended for couples during pregnancy and after birth, and is open to the general public. The program focuses on giving tools for conflict management, problem-solving, communication and support that encourage collaborative parenting. These tools are learned by psycho-educationally oriented discussions of topics 
like sharing the burden and providing appropriate stimuli to the child. The program is comprised of a series of eight meetings, before and after birth, for both parents. Each group is made up 6 - 10 couples, and is facilitated by a male and female team of therapists who have undergone special training.

Intervention effectiveness: A random controlled study on 169 couples during the period of a first pregnancy found positive outcomes-a significant improvement in the level of cooperation between members of the couple, a decrease in the level of the mother's depression, the couple's anxiety, and the stress regarding the parent-child relationship. The study also showed an increase in the child's self-regulation and quality of sleep. A higher impact was found among the low socio-economic population. The researchers conclude that the cooperation program can have a positive impact especially for at-risk families.

Additional factors recommended when planning and designing intervention programs for the period of pregnancy:

- A planned approach including treatment of a number of parenting components has the greatest impact [76];

- A continuum of at least 11 meetings over 3 months, and supportive and sensitive accompaniment of staff operating the program [77].

\subsection{Overview of Mixed Programs for Single-Parent Mothers}

Background: There are four known studies that examined the effects of intervention programs for singleparent mothers of children with behavioral problems and children diagnosed with ADHD. Among these, the only study that included a Clinical Controlled Trial was performed by Chacko et al., (2009) [78].

Intervention course: A behavioral program for single-parent mothers of children aged 5 - 12 diagnosed with Attention Deficit Hyperactivity Disorder (ADHD).

Intervention effectiveness: Study findings showed a significant reduction in dimensions of oppositional behavior and mother's stress level, and improved parent-child interaction and parental behavior. However a significant difference was not found between the experimental group and the control group with regard to dimensions related to symptoms of ADHD in the children and of depression in the mother.

\subsection{Intervention Programs for Fathers}

Background: In the past a greater emphasis was placed on the role of the mother in the process of the child's emotional development, but research today recognizes the importance of the father and even claims that under certain circumstances growing up without a father figure is associated with emotional difficulties in the child [79].

Intervention course: A meta-analysis of 26 studies analyzed the effect of father involvement in parent training programs on program success, and whether the father and mother benefit equally from the program [80].

Intervention effectiveness: The analysis found that studies that included programs in which the father was involved found better outcomes for child behavior and parental conduct that programs that did not include fathers. However there was no difference in the findings of the programs with regard to change in the parent's perception of parenting. In comparison with the mothers, fathers were less likely to implement what they practiced, and reported less on the child's achievements as a result of participation in the program. The researchers conclude that there is a need to involve fathers in parent intervention programs because this increases the likelihood of program success, and recommend further research to learn how to adapt the programs to meet the particular needs of fathers [81].

\subsection{Healthy Family America for At-Risk Populations [82] (from the Program Web-Site http://www.healthyfamiliesamerica.org/home/index.shtml)}

Target population: Families with children from birth to age 3 - 5 who live in poverty in the United States, and whose children are at risk of abuse and neglect.

The program is also suitable for families with histories of trauma, domestic violence, mental health or substance abuse.

Goals and rationale: Promoting positive parenting, strengthening health and child development and preventing child abuse and neglect by identifying families at risk and providing early intervention. The emphasis in the programs is on developing the parent's strengths rather than focusing on his weaknesses, and creating a healthy 
attachment between the parent and child. An additional emphasis is on providing families with culturally sensitive services.

Intervention course: HFA services are provided on a voluntary basis and begin during pregnancy. The program offers two primary components-evaluations that determine whether the family is likely to benefit from participation in the program, and weekly home visits to the target population. The program is intensive and longterm (3 to 5 years after the baby's birth). In addition, it provides the family and child with psychological testing and initial screening, support groups, parent training, and groups focused on father involvement. Service providers in the program undergo special training, but are not required to have any academic or therapeutic background.

Intervention effectiveness: Surveys of more than 15 evaluation studies of HFA in 12 states showed the following results: A reduction in poor treatment of children, improved parental care, a decline in premature and low-weight babies, improved parent-child interactions and school preparedness, decreased dependence upon welfare services, greater accessibility to health services and higher rates of vaccinations.

\section{Parent-Child Intervention Programs Prevalent in the World}

This section will survey evidence-based intervention programs.

1) Living with Children was the first parent training program developed by a group of researchers, led by Gerald Patterson of the Oregon Research Center in the United States [83].

Target population: Children between the ages of 3 - 14 who were referred due to behavior problems.

Treatment setting: Clinic, individual therapy opposite a single family.

Tools: Therapist guidebook: “A social learning approach to family intervention”. The guidebook includes a pre-treatment interview with the parent, a questionnaire evaluating the parent's perception of the quality and frequency of his child's behavior, forms guiding the therapist in making telephone calls with parents and forms for the therapist.

The guidebook for parents: "Living with Children" that includes basic concepts and strategies for learning and behavioral management for the parent to learn on his own.

Length of program: An initial meeting of an hour and a half for gathering information and then 6 - 10 brief observations of 25 minutes in the home over a period of two weeks.

Program content: At the core of the program is the guidebook for parents that deal with how children and parents can learn and emphasizes how behavior can be changed through the use of positive reinforcement. The parent learns to perceive himself as the agent of these changes. The therapist teaches the parent to identify specific behaviors that are his targets and then how to build a plan of positive reinforcements (making eye contact, empowerment) and negative reinforcements to cope with this behavior. The plan usually includes a profit and loss table of points for behavior that took place or not, and the goal is that with time the points will themselves become a reward. The parent learns to use the "time out" technique in which the child is isolated from friends and from activities that he enjoys.

Mode of program delivery: Individual meetings with the parent, during which he is tested on the guidebook. In therapy meetings the therapist uses pre-structured scenarios and role plays in order to teach the parent how to build a behavioral plan with his child.

Unique program characteristics: Emphasis on the theoretical learning of behavioral theories in order to develop the capacity to perform transfer and independent building of a behavioral management plan for the child. In addition the program places an emphasis on observations and documentation of the child's behaviors by the parent, and uses a point system as a central tool for changing the child's behavior.

Research support: The program was researched in many controlled studies since 1976 that found that the program produces a significant decrease in undesired behaviors relative to control groups. Follow-up studies show maintenance of program outcomes a year after its completion [2].

Impressions and recommendations: The program is concrete, clear, accessible and detailed. As such, however, it narrows the therapist's therapeutic possibilities. It is appropriate for families that can experience a close connection and are capable of understanding the theoretical materials upon which the program is based.

2) The Incredible Years-the program was developed in 1984 by Carolyn Webster Stratton from the Washington University, USA [84] [85].

Target population: The basic program is intended for children age 2 - 8 with behavioral problems. 
Therapeutic process: Parent groups in the clinic, without children.

Program materials: Can be purchased on the internet.

- Therapist guidebook including questions for guiding parents.

- Training videos, in a variety of languages and including more than 250 video clips of a variety of situations from a parent's day to day life, with guidance on how to behave and how not to behave.

- Guidebook for group leaders.

- Guidebook for parents including the contents of the entire basic program.

Length of program: About 10 - 14 weeks. Parents meet weekly in groups of 8 - 12 people for training meetings lasting about two hours.

Program contents: The program focuses first on teaching the parent how to play with his child in a way that the child leads in order to strengthen the relationship between them. The parent is instructed to use a behavioral points plan to encourage desirable behavior and to use the "time out" technique to cope with unwanted behaviors. In addition the parent is guided to teach his child a process of problem solving, and learns to use self-regulation strategies such as relaxation techniques for stopping negative thoughts and improving communication skills.

Means of program delivery: The therapist serves as an aid for the parent while he develops new attitudes, shares experiences and discusses problems and ways to resolve them. The group format and watching the video clips with a variety of common situations are used for this purpose. After watching videos role plays are done and homework is given out that encourages use of the learned skills in the natural environment.

Unique aspects of the program: Particular emphasis is placed on a participatory approach on the assumption that the therapist will help the parent bring to fruition his knowledge and abilities. In addition the program relies a great deal upon video clips and learning through role playing among parents, without the child being present. The program differs from other programs in its high costs and requirements for special training. A collection of the various books and the training workshops for therapists cost between $\$ 1300$ and $\$ 1700$.

Research support: Over the last 20 years many controlled and peer-reviewed studies have been performed (on different populations from a range of ethnic backgrounds). These studies showed that the program improves parent-child interactions and reduces children's violent behavior and parental rigidity. Studies are currently being performed to examine the program's effectiveness as a prevention program and initial findings show a positive impact on positive parental behaviors, but results are weaker in relation to the child's behavior [2].

Impression and recommendations: This program is evidence-based and provides accessible information supporting implementation by both therapists and parents. It has a significant advantage for therapists in that the video clips concretize the learning and facilitate communication between therapist and parent. The parent benefits from the group format which is less threatening while at the same time providing significant social support. The program's main limitation is its high cost.

3) HNC-Helping the Noncompliant Child

This program was developed during the 1980's by the researchers Rex Forehand and Robert McMahon from George Washington University in the United States.

Target population: Children ages 3 - 8 with inappropriate behavior a lack of compliance with parental demands.

Treatment process: Intensive parent-child sessions in the clinic.

Program materials:

- Therapist handbook (Helping the noncompliant Child: Family based treatment for oppositional behavior, 2003) that provides guidelines for performing an initial evaluation, observations of structured and free parent-child play, and session management. Reading the book alone is not enough in order to put the model into practice, as experience and developmental knowledge are required.

- Researchers developed an instrument for evaluating parents' knowledge about behavioral principles that has been found to be sensitive to the program's intervention, and its use is recommended.

- Self-help book for the parent (Parenting the Strong Willed Child).

Program duration: 12 weeks not including the evaluation process (interview and initial observations), with an average number of 10 weekly sessions of 60 - 90 minutes.

Program content: Phase 1-In this phase the parent is gradually guided in combining three skills (being attentive, reinforcing and ignoring) during the child's free play. The skills are learned during therapy sessions and practiced at home, and there are criteria that the parent must meet in order to show that he has learned. 
Phase 2-In this phase the parent learns how to guide the child. He learns how to give clear positive instructions, how to reinforce the following of instructions, and how to use the "time out" technique when instructions are not followed.

In the end there are therapy sessions for practicing transference of the skills beyond the home environment.

Means of program delivery: The skills learned in the two phases are adopted in small steps, at the parent's pace, but there are criteria which the parent needs to meet with regard to each skill, and this enables the therapist to monitor the parent's progress and his readiness to move on to the next phase. The therapist uses role playing and feedback, and also shares the program components with the child.

Unique characteristics of the program: The child's level of participation in therapy sessions, the active role provided him and the rigid structure whereby the therapist decides when the parent moves from one phase to the next are unique to this program. A unique aspect of the program handbook is its extensive and detailed discussion on theory.

Research support: Controlled studies performed during the 1970's showed positive outcomes of behavioral change and maintenance of desired child and parent behavior. There were also positive findings of program generalization as well as an improvement in parents' perceptions of their child. Follow up studies performed about ten years after program end showed maintenance of the acquired habits and skills. Studies are currently being performed to examine the program's effectiveness as a prevention program with at-risk populations, and there are positive findings that support its use as a community-based prevention program [2].

Impression and recommendations: The program is composed of different components that have been studied in depth and found effective. The guidebook provides a great deal of background information but less specific practice guidelines, so the program is oriented to therapists with basic knowledge and experience in therapy based on behaviorist principles.

4) PCIT-Parent Child Interaction Therapy.

The program was developed in the 1980's by Sheila Eyberg from Oregon University, USA.

Target population: Children aged 2 - 8 displaying behavioral difficulties. The guidebook claims that the program can also help children with anxiety, low self-esteem, developmental difficulties related to intellectual disabilities, abuse, neglect, divorce and adoption.

Treatment course: Individual clinic-based format, usually together with the child.

Program materials:

- Therapist guidebook ("Parent Child Interaction Therapy”) containing information about the program and detailed guidelines how to manage the evaluation process and the therapy sessions. The guidebook includes standardized scales for performing the evaluation, one of which was developed by the program.

- The program relies mostly on a training technique in which the therapist observes the parent and child through a one-way mirror, and gives the parent instructions through an earphone.

Program length: Between 8 - 14 weeks of weekly meetings lasting 90 minutes.

Program content: The program begins with an evaluation that includes observations of free and structured parent-child play. In the first phase, sessions are held only with the parents, who learn techniques for letting the child lead in free play. Through discussion, role plays and home exercises the parent is taught how to describe appropriate behavior, to imitate play and to give praise and reinforcements in the course of play. The condition for moving on to the next stage is an observation of the parent and the child in which the therapist evaluates according to pre-established criteria whether the parent has acquired the skills.

In the second phase the parent learns through practice in the clinic and at home-basic strategies for coping with the child's oppositional behavior: The parent is guided to gradually mediate and to break down instructions into small steps, first with simple play instructions, and later in real life situations.

Program delivery: Each session in a given phase has a chapter in the handbook with guidelines on how to teach the parent and a chapter with guidelines how to train the parent in real-time when he is practicing with the child. There is a structured and detailed protocol on how to use the "time out" technique and how to prepare a graph of parental progress for purposes of monitoring.

Characteristics unique to the program: The program is based on the topic of secure parent-child attachment and emphasizes imitation and reflection in the course of interaction, contributing to the creation of a secure atmosphere that is responsive and sensitive to the needs of the child. The program is unique in its use of observations and instructions from behind a one-way mirror. Similarly, the program describes in depth the way in which the parent can teach the child and places particular emphasis upon practicing situations of responsiveness and 
obedience at home.

Research support: The first controlled experiment evaluating the program found significant positive effects from the use of the two program phases upon the behavior of both child and parent, in contrast to didactic parenting groups or groups that received no intervention. Studies over the past 20 years that evaluated the program found additional positive results, including generalization of the improvement in skills to the learning environment (school) and its maintenance after conclusion of treatment [86].

Impression and recommendations: The program includes considerable detail on how and what to teach, making it ideal for the beginning therapist, but the observations and evaluations in the second program phase are not sufficiently uniform or clear.

\section{Popular Intervention Programs That Are Not Evidence-Based}

A number of programs that lack firm research support are nonetheless broadly implemented. The main ones are discussed below:

1) PET—Parent Effectiveness Training.

Target population: Children of all ages; Treatment setting-Provided by trained facilitators in either individual or group formats; Children over the age of 12 can participate in groups with the parents.

Program materials: Program materials can be purchased on the internet, including: Guidebook, audio-cassettes, and a basic course for parents and facilitators on how to transmit the program. It is also possible to undergo training workshops in order to become an authorized trainer in the program.

Program duration: Eight weeks during which the parents meet once a week in groups of 8 - 16, for three hours at a time.

Program content: At the heart of the program is the practicing of the "active listening" technique designed to create a warm and accepting relationship between the parent and child. The parent is taught to help the child find appropriate solutions to his needs, rather than to provide them himself. He learns to refrain from giving instruction, advice, or criticism, and instead to focus on active listening in which he reflects back to the child what he thinks the child is trying to express or do. In addition, the program suggests to the parent that he accommodate the environment in some ways, for instance by finding things for the child to do.

Means of program delivery: One needs to participate in a workshop that includes training.

Unique characteristics of the program: The theory that underlies the program is unique in that it gives equal space to the child vis a vis the parent, and encourages active listening and the child's independent finding of solutions. This is the only program in which there is no limitation on the age of participating children, including babies, and in which length of weekly meetings is three hours.

Research support: A meta-analysis performed during the 1990's and in 2001 found that the program had a positive influence on the parent's self-image, but this effect was not statistically significant. In recent years there has been no research support for the program, and it is problematic to compare the different studies that used different research methods. Shriver \& Allen (2008) [2] recommend the program's continued evaluation.

Impression and recommendation: The program can be suitable for a parent interested in developing in the direction of allowing more space, listening and containing, and less in the use of control and limits. The program does not encourage allowing the child to do whatever he wants, and uses environmental adjustments in order to prevent undesirable behaviors. It can support a therapist in promoting positive change in the parent's self image, and there is partial research support for this, but there is no evidence regarding its ability to produce change in the child himself.

2) STEP-Systematic Training for Effective Parenting.

Target population: Primarily for ages 6 - 12 but there are also programs for ages 0 - 6 and adolescents. The program is for the general population and not for parents of children with special behavioral difficulties.

Treatment setting: Parent group without children. No recommendation is made as to the number of participants in a group.

Program materials: Guidebook for therapists (Leaders' Resource Guide) that includes detailed instructions how to lead each meeting, and videos and training books for parents.

Program duration: Recommends 7 weekly meetings lasting 1 - 2 hours.

Program content: At the heart of the program is a philosophy that one should refrain from the use of punishment or rewards of various kinds, and the strategies are identical to those in the PET program-active listen- 
ing, "I statements", and encouraging a democratic family environment.

Program delivery: The user's guide includes detailed and extensive instructions as to how to manage the meeting with the parent, and the parent guidebook includes illustrations of possible scenarios, and suggestions for parents and children in similar situations.

Unique program aspects: The program emphasizes relating to the child as a small and equal adult with equal rights, but also encourages the parent to build behavioral tables and objectives.

Research support: An extensive evaluation was carried out on the program but it did not apply evidence-based methodologies. Some of the studies that met evidence-based methodological criteria found positive outcomes for parental self-image, and increased trust in the parent-child relationship. But other studies done in parallel did not find significant improvement [2].

Impression and recommendations: The program can be suitable when a therapist wants to encourage a parent to control the child less and to be more accepting and supportive. A significant advantage for the therapist is the guidebook that provides detailed guidelines. However, the assumption underlying the program that the child should be related to as a small adult with equal rights, is subject to controversy in light of developmental research that claims that the child should be related to in age-appropriate ways. In addition the program is oriented only toward the normal population, and does not offer a solution for coping with children with significant behavioral problems.

3) Triple P-Positive Parenting Program (USA).

The program is designed to prevent acute emotional and behavioral situations for children by strengthening their parents' knowledge, skills and confidence.

Target population: Ages 0 - 16, for both regular and at-risk populations.

Treatment setting: Individual or group sessions or self-learning by parent.

Program materials: Therapist guidebook that can be purchased on the program's website, aid and assistance through training material on the site and enrichment workshops for therapists.

Program duration: 8 - 10 meetings of one to one and a half hours.

Program content: Emphasis is placed on the parent's development of skills. The program includes five different levels of intervention: Information, selective intervention, focused parent training (up to four sessions for parents of children with minor behavior problems), expanded parent training (8 - 10 meetings alone/group/selftraining).

Program delivery: A variety of media are used, from telephone consultations till family interventions. The therapist uses an active therapy approach that includes modeling, watching videos, role playing, practice, and homework.

Research support: A meta-analysis of 24 relevant studies performed in 2007 for interventions for 3 - 12 year olds concluded that the various interventions have a positive effect, depending on the length and type of intervention [2].

Impression and recommendations: The program is intended for families with children of a broad range of ages, from pre-school to high school. It is flexible and can be adapted to normative or high-risk populations. The program encourages the reduction of risk factors for children's developing behavioral and emotional problems by increasing knowledge, skills, and self-confidence of parents.

4) EHS—Early Head Start (USA).

Program description: A community program developed and financed by the United States federal government. The program began operating in 1995 and as of 2010 there are about 1008 programs implemented in states throughout the USA, in Columbia, Puerto Rico and the Virgin Islands, with services being provided to over 133,000 children under the age of three. The program focuses on promoting the development of infants and toddlers by strengthening the family, promoting parenting abilities among pregnant women and improving family functioning [87].

Target population: pregnant women and families with children up to the age of 3.

Treatment setting: Services are provided in child development centers and in home visits.

Program materials: No materials are specified but a great deal of educational and counseling information is available of the program's web-site (http://www.ehsnrc.org).

Program duration: Provided in the community until age 3 without limitation. Average family participation in the program is 20 - 23 months, with the child receiving an average of 1391 hours of care in the centers.

Program content: The program uses a variety of strategies such as medical and educational counseling to the 
parent, provision of information on child development, referral to para-medical services, emotional therapies and group activities coordinated by the family's case manager, and provision of ongoing support to the family [88]. All content must meet standards set by the program, and federal inspectors are sent every three years to every program site to review its implementation.

Program delivery: Following an evaluation of the needs of the locality the program directors decide whether to use the support center model, home visits, or a combination of the two. Treatments are given to the family itself. Support centers provide mostly child development services such as educational counseling and consultation to the parent and a minimum of two home visits per family per year. In the home visiting program developmental and counseling services are provided through weekly visits and at least two social activities for the parent each month [89]. Program counselors come from the areas of education, educational counseling and therapy, and undergo a special training in the program content and receive intensive supervision for as long as they work.

Unique program characteristics: The program provides a variety of services at a horizontal-community level, and focuses both on the developmental aspect and on the strengthening of the overall family unit in the community. The program is widely funded by the federal government and this has made widespread implementation possible. Regularly scheduled monitoring evaluates and oversees program implementation.

Research support: The program invests resources and attributes great importance to the performance of research. It was evaluated in a random study that included 3001 families in 17 different programs. The research population was diverse in relation to ethnicity, language, and other characteristics. Analysis of findings revealed higher performance and a higher level of cognitive and language development among three year old children who had participated in the program. Parents who had participated in the program were more emotionally supportive and provided more learning and language stimulation than a control group and used less physical punishment. The most significant effects were found in programs that offered a combination of home visits and center-based services [87]. A follow-up study done prior to entry in kindergarten on children who participated in the program from birth found positive effects of reduced depression among those children's mothers [90].

Impression and recommendations: The program is appropriate for implementation at the individual and community level in a variety of ways. It has research support and a great deal of encouragement for program research, professional training, and supportive accompaniment of the program staff.

\section{Discussion}

The purpose of this chapter has been to provide an overview of intervention programs for parents, mostly evidence-based, that operate today in Israel and in the world, and to examine meaningful shared characteristics that contribute to their effectiveness and success. It is evident that programs that strengthen parenting through learning and provision of tools of experience and developmental knowledge promote both the parent's and the child's sense of well-being and quality of life [11].

On the basis of the various programs reviewed according to profession, populations, degree of use and extent of research support, the following general components can be emphasized:

- Use of a model that combines knowledge acquisition and active implementation (demonstrating the activity of the adult with the child). For example: Work to improve parental sensitivity to "signs" that the child is transmitting promotes the child's degree of "playfulness", motivation, independence and inquiry, as well as his capacity for social interaction [37].

- Frequency of therapy/counseling sessions - most of the programs include at least 10 sessions at close intervals or community work over a year.

- Intervention point of entry-From early stages of development (including pregnancy). This refers to early detection and beginning of the intervention as early as possible. When the program is defined as a prevention program for couples during pregnancy and after birth it focuses on providing tools for conflict management, problem solving, communication and mutual support that encourage collaborative parenting [75]. Prevention programs demonstrated reductions in percentages of child abuse, child behavioral problems, and closely following pregnancies, as well as an increase in positive and high quality mother-child interactions and improved language development [52].

- Importance of home visits - For relationship and ongoing communication as well as for familiarity with the daily environment. Strengthening the basic structure by "co-parenting”, strengthening the parents' capacity for open and empathic communication, for resolving disagreements and for working together in the home. 
- A varied and skilled staff from a number of professional disciplines.

- Multi-system care that includes community components-A diverse multi-disciplinary staff relates to the entire family, with concern for all the physical needs and creation of a continuum of care through collaboration between all of the relevant systems and relating to broad environmental contexts such as: Integrating the intervention into the family routine so as not to create burden and role conflict, and to contribute to the parent's quality of life and the family's wellbeing [44]. The therapist should have a good understanding of the home environment and of the objects there, and should integrate intervention into the family routine and daily play situations [45].

- Integrating interventions with daily life-In a group intervention program of occupational therapists on the topic of time management and improving mothers' occupational behavior participants exhibited a high level of satisfaction from the support and various strategies they learned to improve time management in family day-to-day life (such as setting family rules, delegating responsibilities, juggling time demands and more [38]. It was found that routine use of programs of physical fitness and healthy living education can reduce long-term problems. It is evident that the family environment is particularly important in early childhood for developing food preferences, eating habits and style, and physical exercise habits.

- Use of diverse media for training: training videos, filming sessions and jointly viewing them. The goal of the primary intervention is to strengthen and encourage the parent's sensitive and accommodating response to signs that his child shows. This is accomplished by filming the parent and child and providing feedback (the parent essentially serves as his own model).

- Accessibility-work "at eye level"-Professionals "see" parents as whole people with needs and difficulties, with a need for mutual respect and egalitarian relationships; this is essential to creating a true parallel process at all levels that will lead to meaningful change (Packer, 2000; Rivkin \& Yadgar, 2010). Clear and understandable language is used that is suitable and accessible to the specific population. As a rule, the intervention creates a "space" for sharing feelings, expressing frustration, developing reflective thinking, giving legitimacy and finding alternative client-focused solutions through a dynamic process. The closeness, the personal relating, and simulation of life situations, are the basis of program success (Katzir, 2008). Intervention processes expand the parents' repertoire of adaptive responses, and reinforce their strengths and abilities, as well as those of their children, while focusing on simple and easily applied psycho-educational principles.

- Therapist discourse and supervision on supervision-Structured supervision of professionals on multi-disciplinary staffs is essential as it provides a space to talk about the complexity of the work with parents and children (Packer, 2000; Katzir, 2008).

\section{Conclusion}

In summary it can be said that the central theme that arises from the study is that of the parent as a central figure who leads, feels, designs and educates his child. Parent training at the various levels, needs to be client-focused (parent, child) and situation-focused with an emphasis on learning and the need for consistency in managing parent-child interactions. Every intervention needs to begin with evaluating needs and choosing whether to use a center-based model to which parents come with their children, or home visiting or a combination of both, with treatment being family-focused. Below we will set out the intervention model itself in accordance with the central principles mentioned above which were found to be most effective in promoting both the parent and the child's sense of well-being and quality of life.

\section{Acknowledgements}

Thank all members of the Haifa University Interdisciplinary Clinical Center and the Faculty of Social Welfare \& Health Sciences in Haifa University who contributed to this review article.

\section{References}

[1] Greenbaum, C.W. and Fried, D. (2011) Relations between the Family and the Early Childhood Education System (Preschool to Grade 3) Status Report and Recommendations. The Initiative for Applied Education Research.

[2] Shriver, M.D. and Allen, K.D., Eds. (2008) Working with Parents of Noncompliant Children: A Guide to EvidenceBased Parent Training for Practitioners and Students. American Psychological Association, Washington DC.

[3] Piquero, A.R., Farrington, D.P., Welsh, B.C., Tremblay, R. and Jennings, W.G. (2009) Effects of Early Family/Parent 
Training Programs on Antisocial Behavior and Delinquency. Journal of Experimental Criminology, 5, 83-120. http://dx.doi.org/10.1007/s11292-009-9072-x

[4] Thomas, R. and Zimmer-Gembeck, M.J. (2007) Behavioral Outcomes of Parent-Child Interaction Therapy and Triple P-Positive Parenting Program: A Review and Meta-Analysis. Journal of Abnormal Child Psychology, 35, 475-495. http://dx.doi.org/10.1007/s10802-007-9104-9

[5] Scott, S., O’Connor, T. and Futh, A. (2006) What Makes Parenting Programmes Work in Disadvantaged Areas. The PALS Trial.

[6] Piquero, A.R., Farrington, D.P. and Blumstein, A. (2003) The Criminal Career Paradigm. In: Tonry, M., Ed., Crime and Justice: A Review of Research, University of Chicago Press, Chicago.

[7] Wade, S.L. (2004) Commentary: Computer-Based Interventions in Pediatric Psychology. Journal of Pediatric Psychology, 29, 269-272. http://dx.doi.org/10.1093/jpepsy/jsh035

[8] Reyno, S.M. and McGrath, P.J. (2006) Predictors of Parent Training Efficacy for Child Externalizing Behavior Problems-A Metaanalytic Review. Journal of Child Psychology and Psychiatry, 47, 99-111. http://dx.doi.org/10.1111/j.1469-7610.2005.01544.x

[9] Champion, L.A., Goodall, G. and Rutter, M. (1995) Behavior Problems in Children and Stressors in Early Adult Life. I. A 20 Year Follow-Up of London School Children. Psychological Medicine, 25, 231-246. http://dx.doi.org/10.1017/S003329170003614X

[10] Moffitt, T.E. (1993) Life-Course-Persistent and Adolescence-Limited Antisocial Behavior: A Developmental Taxonomy. Psychological Review, 100, 674-701. http://dx.doi.org/10.1037/0033-295X.100.4.674

[11] Oren, D. (2011) Parenthood Treatment. (In Hebrew)

[12] Wyatt Kaminski, J., Valle, L.A., Filene, J.H. and Boyle, C.L. (2008) A Meta-Analytic Review of Components Associated with Parent Training Program Effectiveness. Journal of Abnormal Child Psychology, 36, 567-589. http://dx.doi.org/10.1007/s10802-007-9201-9

[13] Salas, E. and Cannon-Bowers, J.A. (2001) The Science of Training: A Decade of Progress. Annual Review of Psychology, 52, 471-499. http://dx.doi.org/10.1146/annurev.psych.52.1.471

[14] Swanson, H.L. and Hoskyn, M. (2001) Instructing Adolescents with Learning Disabilities: A Component and Composite Analysis. Learning Disabilities Research and Practice, 16, 109-119. http://dx.doi.org/10.1111/0938-8982.00012

[15] Barth, R.P., Landsverk, J., Chamberlain, P., Reid, J.B., Rolls, J.A., Hurlburt, M.S., et al. (2005) Parent-Training Programs in Child Welfare Services: Planning for a More Evidence-Based Approach to Serving Biological Parents. Research on Social Work Practice, 15, 353-371. http://dx.doi.org/10.1177/1049731505276321

[16] Barlow, J. and Stewart-Brown, S. (2000) Behavior Problems and Group-Based Parent Education Programs. Journal of Developmental and Behavioral Pediatrics, 21, 356-370. http://dx.doi.org/10.1097/00004703-200010000-00007

[17] Roffwarg, H.P., Muzio, J.N. and Dement, W.C. (1966) Ontogenetic Development of the Human Sleep-Dream Cycle. Science, 152, 604-619. http://dx.doi.org/10.1126/science.152.3722.604

[18] Mindell, J.A., Kuhn, B., Lewin, D.S., Meltzer, L.J., Sadeh, A. and American Academy of Sleep Medicine (2006) Behavioral Treatment of Bedtime Problems and Night Wakings in Infants and Young Children. Sleep, 29, 1263-1276.

[19] Ednick, M., Cohen, A.P., McPhail, G.L., Beebe, D., Simakajornboon, N. and Amin, R.S. (2009) A Review of the Effects of Sleep during the First Year of Life on Cognitive, Psychomotor and Temperament Development. Sleep, 32, 1449-1458.

[20] Scher, A., Hall, W.A., Zaidman-Zait, A. and Weinberg, J. (2010) Sleep Quality, Cortisol Levels and Behavioral Regulation in Toddlers. Developmental Psychobiology, 52, 44-53.

[21] Tikotzky, L. and Sadeh, A. (2010) The Role of Cognitive-Behavioral Therapy in Behavioral Childhood Insomnia. Sleep Medicine, 11, 686-691. http://dx.doi.org/10.1016/j.sleep.2009.11.017

[22] Meltzer, L.J. and Mindell, J.A. (2006) Sleep and Sleep Disorders in Children and Adolescents. Psychiatric Clinical North Amsterdam, 29, 1059-1076. http://dx.doi.org/10.1016/j.psc.2006.08.004

[23] American Academy of Sleep Medicine (2005) International Classification of Sleep Disorders: Diagnostic and Coding Manual. 2nd Edition, American Academy of Sleep Medicine, Westchester.

[24] Lam, P., Hiscock, H. and Wake, M. (2003) Outcomes of Infant Sleep Problems: A Longitudinal Study of Sleep, Behavior and Maternal Well-Being. Pediatrics, 111, e203-e207. http://dx.doi.org/10.1542/peds.111.3.e203

[25] Bayer, J.K., Hiscock, H., Hampton, A. and Wake, M. (2007) Sleep Problems in Young Infants and Maternal Mental and Physical Health. Journal of Paediatrics and Child Health, 43, 66-73. http://dx.doi.org/10.1111/j.1440-1754.2007.01005.x

[26] Wolfson, A., Lacks, P. and Futterman, A. (1992) Effects of Parent Training on Infant Sleeping Patterns, Parents' Stress and Perceived Parental Competence. Journal of Consulting and Clinical Psychology, 60, 41-48. 
http://dx.doi.org/10.1037/0022-006X.60.1.41

[27] Kerr, S.M., Jowett, S.A. and Smith, L.N. (1996) Preventing Sleep Problems in Infants: A Randomized Controlled Trial. Journal of Advanced Nursing, 24, 938-942. http://dx.doi.org/10.1111/j.1365-2648.1996.tb02929.x

[28] Stremler, R., Hodnett, E., Lee, K., MacMillan, S., Mill, C., Ongcangco, L. and Willan, A. (2006) A Behavioral-Educational Intervention to Promote Maternal and Infant Sleep: A Pilot Randomized, Controlled Trial. Sleep, 29, 1609-1615.

[29] Morin, C.M., Bootzin, R.R., Buysse, D.J., Edinger, J.D., Espie, C.A. and Lichstein, K.L. (2006) Psychological and Behavioral Treatment of Insomnia: Update of the Recent Evidence (1998-2004). Sleep, 29, 1398-1414.

[30] Riemann, D. and Perlis, M.L. (2009) The Treatments of Chronic Insomnia: A Review of Benzodiazepine Receptor Agonists and Psychological and Behavioral Therapies. Sleep Medicine Reviews, 13, 205-214. http://dx.doi.org/10.1016/j.smrv.2008.06.001

[31] Sadeh, A. (2005) Cognitive-Behavioral Treatment for Childhood Sleep Disorders. Clinical Psychology Review, 25, 612628. http://dx.doi.org/10.1016/j.cpr.2005.04.006

[32] Hanzlik, J.R. (1998) Parent-Child Relations: Interaction and Intervention. In: Case-Smith, J., Ed., Pediatric Occupational Therapy and Early Intervention, 2nd Edition, Butterworth-Heinemann, Boston, 207-222.

[33] Parush, S. and Hann-Markowitz, J. (1996) The Efficacy of an Early Prevention Program Facilitated by Occupational Therapists: A Follow-Up Study. American Journal of Occupational Therapy, 51, 247-251. http://dx.doi.org/10.5014/ajot.51.4.247

[34] Esdaile, S.A. (1996) A Play-Focused Intervention Involving Mothers of Preschoolers. American Journal of Occupational Therapy, 50, 113-123. http://dx.doi.org/10.5014/ajot.50.2.113.

[35] Dreiling, D.S. and Bundy, A.C. (2003) Brief Report-A Comparison of Consultative Model and Direct-Indirect Intervention with Preschoolers. American Journal of Occupational Therapy, 57, 566-569. http://dx.doi.org/10.5014/ajot.57.5.566

[36] Sajaniemi, N., Mäkelä, J., Salokorpi, T., von Wendt, L., Hämäläinen, T. and Hakamies-Blomqvist, L. (2000) Cognitive Performance and Attachment Patterns at Four Years of Age in Extremely Low Birth Weight Infants after Early Intervention. European Child \& Adolescent Psychiatry, 10, 122-129. http://dx.doi.org/10.1007/s007870170035

[37] Okimoto, A.M., Bundy, A. and Hanzlik, J. (2000) Playfulness in Children with and without Disability: Measurement and Intervention. American Journal of Occupational Therapy, 54, 73-82. http://dx.doi.org/10.5014/ajot.54.1.73

[38] VanLeit, B. and Crowe, T.K. (2002) Outcomes of an Occupational Therapy Program for Mothers of Children with Disabilities: Impact on Satisfaction with Time Use and Occupational Performance. American Journal of Occupational Therapy, 56, 402-410. http://dx.doi.org/10.5014/ajot.56.4.402

[39] Helitzer, D.L., Cunningham-Sabo, L.D. VanLeit, B. and Crowe, T.K. (2002) Perceived Changes in Self-Image and Coping Strategies of Mothers of Children with Disabilities. The Occupational Therapy Journal of Research, 22, 25-33.

[40] Mayer, M.L., White, B.P., Ward, J.D. and Barnaby, E.M. (2002) Therapists’ Perceptions about Making a Difference in Parent-Child Relationships in Early Intervention Occupational Therapy Services. American Journal of Occupational Therapy, 56, 411-421. http://dx.doi.org/10.5014/ajot.56.4.411

[41] Colyvas, J.L., Sawyer, L.B. and Campbell, P.H. (2010) Identifying Strategies Early Intervention Occupational Therapists Use to Teach Caregivers. American Journal of Occupational Therapy, 64, 776-785. http://dx.doi.org/10.5014/ajot.2010.09044

[42] Crowe, T.K. (1993) Time Use of Mothers with Young Children: The Impact of a Child’s Disability. Developmental Medicine Child Neurology, 35, 621-630. http://dx.doi.org/10.1111/j.1469-8749.1993.tb11700.x

[43] Crowe, T.K. and Florez, S.I. (2006) Time Use of Mothers with School-Age Children: A Continuing Impact of a Child's Disability. American Journal of Occupational Therapy, 60, 194-203. http://dx.doi.org/10.5014/ajot.60.2.194

[44] Segal, R. and Beyer, C. (2006) Integration and Application of a Home Treatment Program: A Study of Parents and Occupational Therapists. American Journal of Occupational Therapy, 60, 500-510. http://dx.doi.org/10.5014/ajot.60.5.500

[45] Pierce, D., Munier, V. and Myers, C.T. (2009) Informing Early Intervention through an Occupational Science Description of Infant-Toddler Interactions with Home Space. American Journal of Occupational Therapy, 63, 273-287. http://dx.doi.org/10.5014/ajot.63.3.273

[46] Pierce, D. (2000) Maternal Management of the Home as a Developmental Play Space for Infants and Toddlers. American Journal of Occupational Therapy, 53, 290-299. http://dx.doi.org/10.5014/ajot.54.3.290

[47] Ketelaar, M., Vermeer, A., Helders, P.J.M. and Hart, H. (1989) Parental Participation in Intervention Programs for Children with Cerebral Palsy. Topics in Early Childhood Special Education, 18, 108-117. http://dx.doi.org/10.1177/027112149801800206

[48] Hanzlik, R.J. (1989) The Effect of Intervention on the Free-Play Experience for Mothers and Their Infants with Deve- 
lopmental Delay and Cerebral Palsy. Physical \& Occupational Therapy in Pediatrics, 9, 33-51. http://dx.doi.org/10.1300/J006v09n02_04

[49] Lekskulchai, R. and Cole, J. (2001) Effect of a Developmental Program on Motor Performance in Infants Born Preterm. Australian Journal of Physiotherapy, 47, 169-176. http://dx.doi.org/10.1016/S0004-9514(14)60264-6

[50] Norman, E., Sherburn, M., Osborne, R.H. and Galea, M.P. (2010) An Exercise and Education Program Improves Wellbeing of New Mothers: A Randomized Controlled Trial. Physical Therapy, 90, 348-355. http://dx.doi.org/10.2522/ptj.20090139

[51] Hielkema, et al. (2010) Learn 2 Move 0-2 Years: Effects of a New Intervention Program in Infants at Very High Risk for Cerebral Palsy; a Randomized Controlled Trial. BMC Pediatrics, 10, 76. http://dx.doi.org/10.1186/1471-2431-10-76

[52] Olds, D.L., Kitzman, H.J., Cole, R.E., Hanks, C.A., Arcoleo, K.J., Anson, E.A., Luckey, D.W., Knudtson, M.D., Henderson Jr., C.R., Bondy, J. and Stevenson, A.J. (2010) Enduring Effects of Prenatal and Infancy Home Visiting by Nurses on Maternal Life Course and Government Spending: Follow-Up of a Randomized Trial among Children at Age 12 Years. Archives of Pediatrics \& Adolescent Medicine, 164, 419-424. http://dx.doi.org/10.1001/archpediatrics.2010.49

[53] Karmiloff, K. and Karmiloff-Smith, A. (2001) Pathways to Language. Harvard University Press, Cambridge, Massachusetts.

[54] Crain-Thoreson, C. and Dale, P.S. (1999) Enhancing Linguistic Performance: Parents and Teachers as Book Reading Partners for Children with Language Delays. Topics in Early Childhood Special Education, 19, 28-39. http://dx.doi.org/10.1177/027112149901900103

[55] Whitehurst, G.J., Arnold, D.S., Epstein, J.N., Angell, A.L., Smith, M. and Fishcel, J.E. (1994) A Picture Book Reading Intervention in Day Care and Home for Children from Low-Income Families. Developmental Psychology, 30, 679-689. http://dx.doi.org/10.1037/0012-1649.30.5.679

[56] Bruner, J.S. (1990) Acts of Meaning. Harvard University Press, Cambridge, Massachusetts.

[57] Vygotsky, L. (1978) Mind in Society: The Development of Higher Psychological Processes. Harvard University Press, Cambridge, Massachusetts.

[58] Bennett, K.K., Weigel, D.J. and Martin, S.S. (2002) Children’s Acquisition of Early Literacy Skills: Examining Family Contributions. Early Childhood Research Quarterly, 17, 295-317. http://dx.doi.org/10.1016/S0885-2006(02)00166-7

[59] Hood, M., Conlon, E. and Andrews, G. (2008) Preschool Home Literacy Practices and Children’s Literacy Development: A Longitudinal Analysis. Journal of Educational Psychology, 100, 252-271. http://dx.doi.org/10.1037/0022-0663.100.2.252

[60] The Parent-Child Home Program (2011). http://www.cebc4cw.org/program/the-parent-child-home-program/detailed

[61] Home Instruction for Parents of Preschool Youngsters (2011). http://www.cebc4cw.org/program/home-instruction-for-parents-of-preschool-youngsters/detailed

[62] Birch, L.L. and Davison, K.K. (2001) Family Environmental Factors Influencing the Developing Behavioral Controls of Food Intake and Childhood Overweight. Pediatric Clinics of North America, 48, 893-907. http://dx.doi.org/10.1016/S0031-3955(05)70347-3

[63] Agency for Healthcare Research and Quality (2008) Effectiveness of Weight Management Programs in Children and Adolescents. Rockville, September 2008. Report No. 08-E014.

[64] Nemet, D., Geva, D. and Eliakim, A. (2011) Health Promotion Intervention in Low Socioeconomic Kindergarten Children. Journal of Pediatrics, 158, 796-801.

[65] Field, T., Schanberg, S.M., Scafidi, F., Bauer, C.R., Vega-Lahr, N., Garcia, R., Nystrom, J. and Kuhn, C.M. (1986) Tactile/Kinesthetic Stimulation Effects on Preterm Neonates. Pediatrics, 77, 654-658.

[66] Fonagy, P., Steele, M., Moran, G., Steele, H. and Higgitt, A. (1993) Measuring the Ghost in the Nursery: An Empirical Study of the Relation between Parents' Mental Representations of Childhood Experiences and Their Infants' Security of Attachment. Journal American Psychoanalyze Association, 41, 957-989. http://dx.doi.org/10.1177/000306519304100403

[67] Dozier, M., Peloso, E., Lindhiem, O., Gordon, M.K., Manni, M., Sepulveda, S., Ackerman, J., Bernier, A. and Levine, S. (2006) Developing Evidence-Based Interventions for Foster Children: An Example of a Randomized Clinical Trial with Infants and Toddlers. Journal of Social Issues, 62, 767-785. http://dx.doi.org/10.1111/j.1540-4560.2006.00486.x

[68] Dozier, M., Manni, M., Gordon, M.K., Peloso, E., Gunnar, M.R., Stovall-McClough, K., Eldreth, D. and Levine, S. (2006) Foster Children’s Diurnal Production of Cortisol: An Exploratory Study. Child Maltreatment, 11, 189-197. http://dx.doi.org/10.1177/1077559505285779 
[69] Hoffman, K.T. and Marvin, R.S. (2006) Changing Toddlers’ and Preschoolers’ Attachment Classifications: The Circle of Security Intervention. Journal of Consulting and Clinical Psychology, 74, 1017-1026. http://dx.doi.org/10.1037/0022-006X.74.6.1017

[70] Kalinauskiene, L., Cekuoliene, D., Van IJzendoorn, M.H., Bakermans-Kranenburg, M.J., Juffer, F. and Kusakovskaja, I. (2009) Supporting Insensitive Mothers: The Vilnius Randomized Control Trial of Video Feedback Intervention to Promote Maternal Sensitivity and Infant Attachment Security. Child: Care, Health \& Development, 35, 613-623. http://dx.doi.org/10.1111/j.1365-2214.2009.00962.x

[71] Nielsen Forman, D., Videbech, P., Hedegaard, M., Salvig, J.D. and Secher, N.J. (2000) Postpartum Depression: Identification of Women at Risk. BJOG: An International Journal of Obstetrics \& Gynaecology, 107, 1210-1217. http://dx.doi.org/10.1111/j.1471-0528.2000.tb11609.x

[72] Wadhwa, P.D., Culhane, J.F., Rauh, V., Barve, S.S., Hogan, V., Sandman, C.A., et al. (2001) Stresses, Infection and Preterm Birth: A Biobehavioural Perspective. Paediatric and Perinatal Epidemiology, 15, 17-29. http://dx.doi.org/10.1046/j.1365-3016.2001.00005.x

[73] Bonari, L., Pinto, N., Ahn, E., et al. (2004) Perinatal Risks of Untreated Depression during Pregnancy. Canadian Journal of Psychiatry, 49, 726-735.

[74] Dawson, G., Frey, K., Self, J., Panagiotides, H., Hessl, D. and Yamada, E. (1999) Frontal Brain Electrical Activity in Infants of Depressed and Nondepressed Mothers: Relation to Variations in Infant Behavior. Child Development, 70, 1058-1066. http://dx.doi.org/10.1111/1467-8624.00078

[75] Bergner, S., Monk, C. and Werner, E.A. (2008) Dyadic Intervention during Pregnancy? Treating Pregnant Women and Possibly Reaching the Future Baby. Infant Mental Health Journal, 29, 399-419. http://dx.doi.org/10.1002/imhj.20190

[76] Vieten, C. and Astin, J. (2008). Effects of a Mindfulness-Based Intervention during Pregnancy on Prenatal Stress and Mood: Results of a Pilot Study. Archives of Women's Mental Health, 11, 67-74. http://dx.doi.org/10.1007/s00737-008-0214-3

[77] Feinberg, M.E. and Kan, M.L. (2008) Establishing Family Foundations: Intervention Effects on Coparenting, Parent/Infant Well- Being and Parent-Child Relations. Journal of Family Psychology, 22, 253-263. http://dx.doi.org/10.1037/0893-3200.22.2.253

[78] Cowan, C.P. and Cowan, P.A. (1995) Interventions to Ease the Transition to Parenthood: Why They Are Needed and What They Can Do. Family Relations, 44, 412-423. http://dx.doi.org/10.2307/584997

[79] Chacko, A., Wymbs, B.T., Wymbs, F.A., Pelham, W.E., Swanger-Gagne, M.S., Girio, E., et al. (2009) Enhancing Traditional Behavioral Parent Training for Single Mothers of Children with ADHD. Journal of Clinical Child and Adolescent Psychology, 38, 13. http://dx.doi.org/10.1080/15374410802698388

[80] Harper, C.C. and McLanahan, S.S. (2004) Father Absence and Youth Incarceration. Journal of Research on Adolescence, 14, 369-397. http://dx.doi.org/10.1111/j.1532-7795.2004.00079.x

[81] Lundahl, B.W., Tollefson, D., Risser, H. and Lovejoy, M.C. (2008) A Meta-Analysis of Father Involvement in Parent Training. Research on Social Work Practice, 18, 97-102. http://dx.doi.org/10.1177/1049731507309828

[82] Healthy Family America (2011). http://www.healthyfamiliesamerica.org/home/index.shtml

[83] Patterson, G.R. (1982) Coercive Family Process. Castalia, Eugene.

[84] Webster-Stratton, C. and Hammond, M. (1998) Conduct Problems and Level of Social Competence in Head Start Children: Prevalence, Pervasiveness and Associated Risk Factors. Clinical Child Psychology and Family Psychology Review, 1, 101-124.

[85] Webster-Stratton, C. and Herbert, M. (1994) Troubled Families-Problem Children: Working with Parents: A Collaborative Process. John Wiley \& Sons, Oxford.

[86] Hood, K.K. and Eyberg, S.M. (2003) Outcomes of Parent Child Interaction Therapy: Mother’s Report of Maintenance Three to Six Years after Treatment. Journal of Clinical Child and Adolescence Psychology, 32, 419-429. http://dx.doi.org/10.1207/S15374424JCCP3203_10

[87] Love, J.M., Kisker, E.E., Ross, C., Raikes, H., Constantine, J., Boller, K. and Vogel, C. (2005) The Effectiveness of Early Head Start for 3-Year-Old Children and Their Parents: Lessons for Policy and Programs. Developmental Psychology, 41, 885-901. http://dx.doi.org/10.1037/0012-1649.41.6.885

[88] U.S. Department of Health and Human Services, Administration for Children and Families (1995) Early Head Start Program Grant Availability: Notice. Federal Register, 60, 14548-14578.

[89] Administration for Children and Families (2002) Pathways to Quality and Full Implementation in Early Head Start Programs. Department of Health and Human Services, Washington DC.

[90] Chazan-Cohen, R., Ayoub, C., Pan, B.A., Roggman, L., Raikes, H., Mckelvey, L., Whiteside-Mansell, L. and Hart, A. (2007) It Takes Time: Impacts of Early Head Start That Lead to Reductions in Maternal Depression Two Years Later. Infant Mental Health Journal, 28, 151-170. http://dx.doi.org/10.1002/imhj.20127 
Scientific Research Publishing (SCIRP) is one of the largest Open Access journal publishers. It is currently publishing more than 200 open access, online, peer-reviewed journals covering a wide range of academic disciplines. SCIRP serves the worldwide academic communities and contributes to the progress and application of science with its publication.

Other selected journals from SCIRP are listed as below. Submit your manuscript to us via either submit@scirp.org or Online Submission Portal.
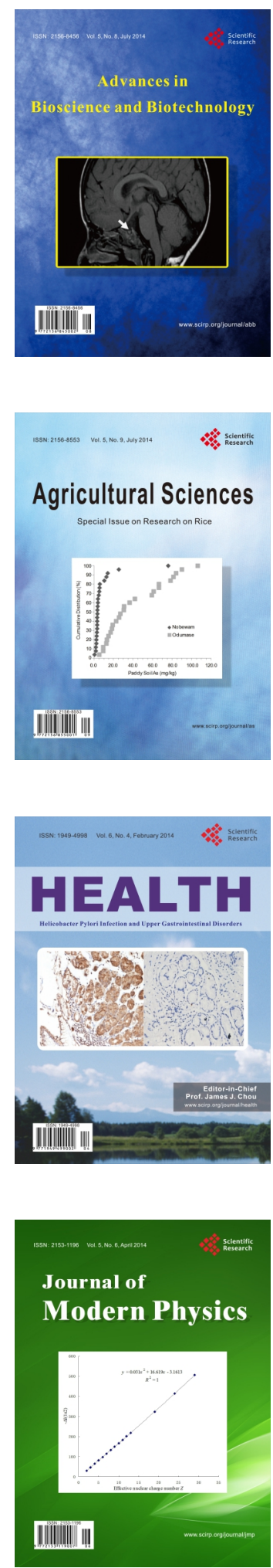
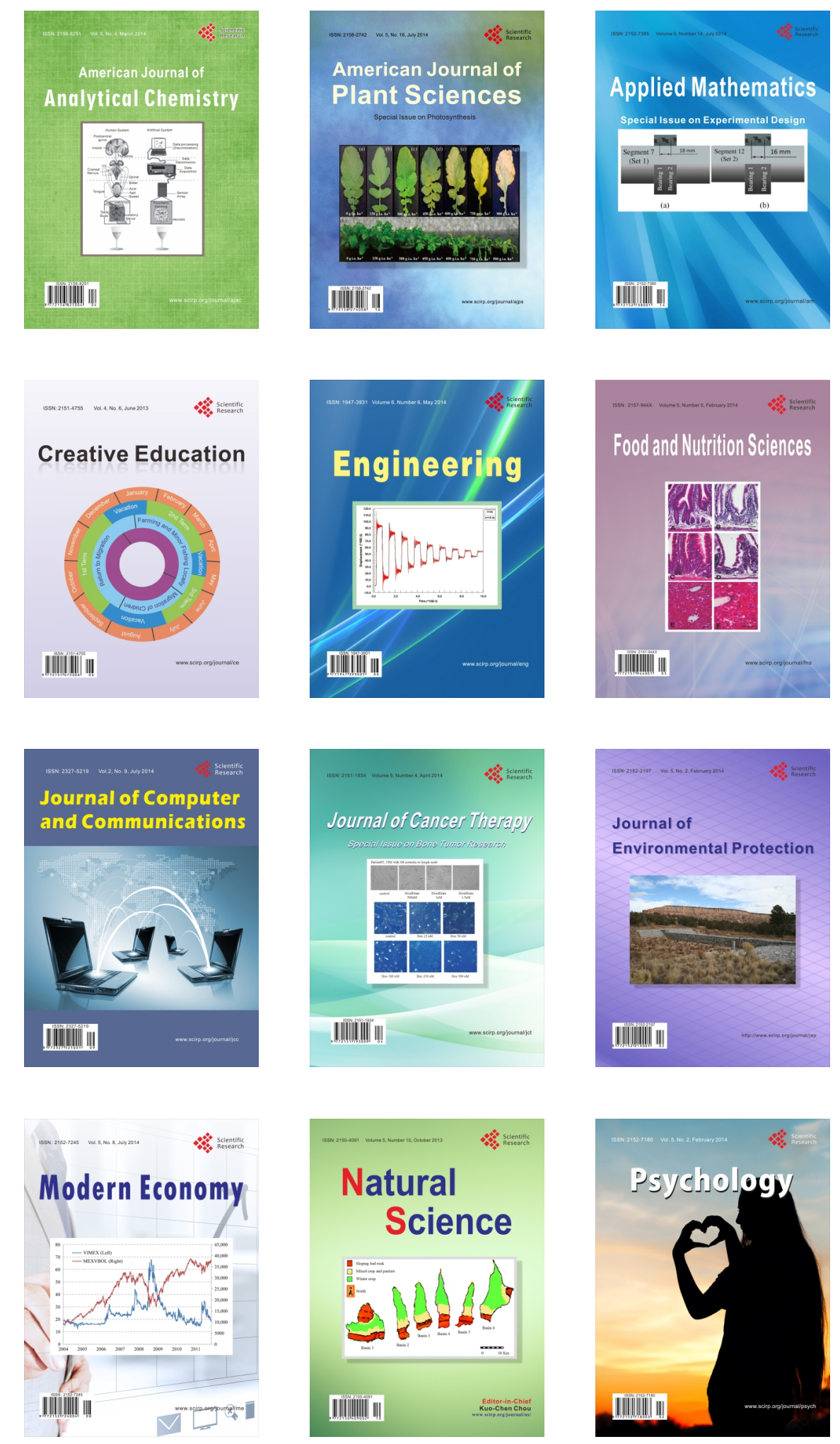